\title{
Bladder Overactivity and Hyperexcitability of Bladder Afferent Neurons after Intrathecal Delivery of Nerve Growth Factor in Rats
}

\author{
Naoki Yoshimura, ${ }^{1,2}$ Nelson E. Bennett, ${ }^{1}$ Yukio Hayashi, ${ }^{1}$ Teruyuki Ogawa, ${ }^{1,3}$ Osamu Nishizawa, ${ }^{3}$ \\ Michael B. Chancellor, ${ }^{1}$ William C. de Groat, ${ }^{2}$ and Satoshi Seki ${ }^{1,2,3}$ \\ Departments of ${ }^{1}$ Urology and ${ }^{2}$ Pharmacology, University of Pittsburgh School of Medicine, Pittsburgh, Pennsylvania 15213, and ${ }^{3}$ Department of Urology, \\ Shinshu University, Matsumoto 390-0802, Japan
}

\begin{abstract}
Nerve growth factor (NGF) has been proposed as an important mediator inducing bladder overactivity under pathological conditions such as spinal cord injury, bladder outlet obstruction, or cystitis. We therefore examined the effects of chronic NGF treatment on bladder activity and the properties of bladder afferent neurons. In adult female rats, $\operatorname{NGF}(2.5 \mu \mathrm{g} / \mu \mathrm{l})$ was infused continuously into the intrathecal space at the L6-S1 level of spinal cord for 1 or 2 weeks using osmotic pumps $(0.5 \mu \mathrm{l} / \mathrm{h})$. Bladder afferent neurons were labeled with axonal transport of Fast Blue injected into the bladder wall. After intrathecal injection of NGF, cystometrograms under an awake condition showed bladder overactivity revealed by time-dependent reductions in intercontraction intervals and voided volume. ELISA analyses showed significant increases in NGF levels in L6-S1 dorsal root ganglia of NGF-treated rats. In patch-clamp recordings, dissociated bladder afferent neurons exhibiting tetrodotoxin (TTX)-resistant action potentials from NGF-treated animals were larger in diameter and had significantly lower thresholds for spike activation compared with sham rats. In addition, the number of TTX-resistant action potentials during $600 \mathrm{~ms}$ depolarizing pulses was significantly increased time dependently after 1 or 2 weeks of NGF application. The density of slowly inactivating A-type $\mathrm{K}^{+}$currents was decreased by $52 \%$ in bladder afferent neurons with TTX-resistant spikes after 2 week NGF treatment. These results indicate that increased NGF levels in bladder afferent pathways and NGF-induced reduction in A-type $\mathrm{K}^{+}$current density could contribute to the emergence of bladder overactivity as well as somal hypertrophy and hyperexcitability of bladder afferent neurons.
\end{abstract}

Key words: nerve growth factor; rat; dorsal root ganglion; urinary bladder; $\mathrm{Na}^{+}$current; $\mathrm{K}^{+}$current

\section{Introduction}

It has been demonstrated that afferent pathways innervating the urinary bladder consist of myelinated A $\delta$-fibers and unmyelinated C-fibers and that hyperexcitability of C-fibers in bladder afferent pathways contributes to bladder overactivity and/or bladder pain under pathological conditions such as spinal cord injury or chronic cystitis (Yoshimura, 1999; Yoshimura et al., 2002; Chancellor and Yoshimura, 2002).

Nerve growth factor (NGF) has been proposed as one of the key molecules responsible for C-fiber hyperexcitability in these pathological conditions because (1) NGF levels in the bladder and/or the spinal cord as well as in lumbosacral dorsal root ganglia (DRGs) were increased in animals with spinal cord injury or chronic cystitis that exhibited bladder overactivity (Vizzard, 2000; Seki et al., 2002, 2004), (2) autoimmunization against NGF suppresses bladder overactivity and somal hypertrophy in blad-

Received July 17, 2006; revised Sept. 1, 2006; accepted Sept. 1, 2006.

This work was supported by National Institutes of Health Grants DK57267, DK68557, DK66138, and P01HD39768. Correspondence should be addressed to Dr. Naoki Yoshimura, Department of Urology, University of Pittsburgh School of Medicine, Suite 700, Kaufmann Medical Building, 3471 Fifth Avenue, Pittsburgh, PA 15213. E-mail: nyos@pitt.edu.

DOI:10.1523/JNEUROSCI.3023-06.2006

Copyright $\odot 2006$ Society for Neuroscience $\quad$ 0270-6474/06/2610847-09\$15.00/0 der afferent neurons in animals with bladder outlet obstruction (Steers et al., 1991, 1996), and (3) immunoneutralization of NGF in the lumbosacral spinal cord decreased bladder overactivity induced by hyperexcitable C-fiber afferents in rats with chronic spinal cord injury (Seki et al., 2002). Recent studies have also reported that adenovirus vector-mediated NGF overexpression in the bladder induced bladder overactivity (Lamb et al., 2004) and that a recombinant NGF sequestering protein, REN1820, reduced bladder overactivity in rats with cyclophosphamideinduced cystitis (Hu et al., 2005), suggesting the direct involvement of NGF in the emergence of bladder overactive condition.

We have previously reported that the underlying mechanisms inducing hyperexcitability of bladder afferent neurons in chronic spinal cord injury or chronic cystitis involve altered $\mathrm{Na}^{+}$and/or A-type $\mathrm{K}^{+}$channel activity in rats (Yoshimura and de Groat, 1997; Yoshimura 1999; Yoshimura and de Groat., 1999). Similar changes in $\mathrm{K}^{+}$channels have also been reported by other investigators in animals with inflammation in gastrointestinal organs (Stewart et al., 2003; Dang et al., 2004). In addition, gastric ulcer formation in the rat caused a rise in NGF concentration and an increase in NGF immunoreactivity in the gastric wall (Bielefeldt et al., 2003). Together, these data indirectly suggest that NGF is an important molecule to induce ion channel plasticity, leading to 
hyperexcitability in visceral afferent pathways innervating the bladder and gastrointestinal organs. However, tissue inflammation in the bladder can increase the levels of not only NGF but also other neurotrophic factors such as glial cell line-derived neurotrophic factor or neurotrophin-3 (Vizzard, 2000). Thus, there is no direct evidence indicating that in vivo exposure of NGF can induce hyperexcitability of afferent neurons attributable to changes in $\mathrm{K}^{+}$and/or $\mathrm{Na}^{+}$channel activity similar to those found in visceral organ inflammation.

Therefore, to better characterize the impact of NGF on the bladder and bladder afferent pathways, we performed chronic intrathecal application of NGF at the level of lumbosacral spinal cord, where bladder afferents terminates, to increase the exposure of bladder afferent neurons to NGF, and examined whether NGF-induced bladder overactivity is correlated with changes in excitability and ion channel activity of bladder afferent neurons.

\section{Materials and Methods \\ Animals}

Experiments were performed in adult female Sprague Dawley rats (204$256 \mathrm{~g})$. Care and handling of animals were in accordance with institutional guidelines and approved by the University of Pittsburgh Institutional Animal Care and Use Committee.

\section{Experiment 1: bladder activity and NGF level in DRGs after NGF treatment}

In experimental protocol 1, bladder activity was compared in vehicletreated rats and rats treated with NGF for 1 or 2 weeks. Thereafter, NGF levels in DRGs were measured by ELISA methods.

Intrathecal NGF administration. An intrathecal catheter (PE-10; Clay Adams, Parsippany, NJ) was implanted at the level of the L6-S1 spinal cord after a laminectomy at the Th11 vertebra under halothane anesthesia. The proximal end of catheter was heat-sealed and placed subcutaneously. Animals were recovered from an anesthetic, and buprenophine $(0.05 \mathrm{mg} / \mathrm{kg}$, s.c. $)$ was given to all animals to control postoperative pain. Three to $4 \mathrm{~d}$ after intrathecal catheter implantation, the intrathecal catheter was connected to an osmotic mini pump (model 2001 or 2002; Alza, Palo Alto, CA), which was placed subcutaneously in the back, for continuous delivery $(0.5 \mu \mathrm{l} / \mathrm{h}$ ) of either vehicle (artificial CSF) for 2 weeks or NGF $(2.5 \mu \mathrm{g} / \mu \mathrm{l})$ for either 1 or 2 weeks. Animals were divided into two groups that were subjected to either cystometry followed by ELISA measurements of NGF levels in DRGs ( $n=19$ rats) or patch-clamp recordings in bladder afferent neurons ( $n=21$ rats). Recombinant human NGF was kindly provided by Genentech (South San Francisco, CA). Any behavior suggestive of persistent pain was not observed during NGF administration when the condition of the animals was monitored twice daily by trained laboratory staff.

Cystometry. One or 2 weeks after intrathecal injection of vehicle or NGF, cystometry in conscious rats was performed according to previously published methods (Yaksh et al., 1986). Under halothane anesthesia, a catheter (PE 50) was inserted via a midline abdominal incision into the bladder through the bladder dome, and the abdomen was closed by sutures. Local anesthetic cream containing lidocaine $2.5 \%$ and prilocaine 2.5\% (AstraZeneca, Wilmington, DE) were topically applied to wounds to alleviate skin irritation. After the surgery, rats were placed in a restraining cage and allowed to recover from anesthesia for $1-2 \mathrm{~h}$. The intravesical catheter was connected via a three-way stopcock to a pressure transducer and a syringe pump for recording intravesical bladder pressure and infusing saline into the bladder, respectively. Saline at room temperature was infused at a rate of $0.04 \mathrm{ml} / \mathrm{min}$ to elicit repetitive bladder contractions. The saline infusion was continued for at least $3 \mathrm{~h}$ before measuring voiding parameters.

Saline voided from the urethral meatus was collected and measured to determine voided volume (VV). Intercontraction interval (ICI), maximal voiding pressure (MVP), pressure threshold for voiding (PT), and baseline intravesical pressure (BP) were also measured. After constant VVs were collected, the infusion was stopped and postvoid residual volume was measured: residual saline was withdrawn through the intraves- ical catheter by gravity, and then the bladder was completely emptied by manual compression through the abdominal wall. During cystometry with saline infusion, behavior suggestive of persistent pain such as vocalization or excessive body movements was not observed in any animals.

ELISA analysis. After cystometry, the L5-S1 DRGs were removed under halothane anesthesia from vehicle- or NGF-treated rats. DRG tissues were also obtained from untreated normal rats $(n=3)$. After the tissue removal, animals were killed by an overdose of pentobarbital $(120 \mathrm{mg} / \mathrm{kg}$, i.p.). In L5-S1 DRGs, ELISA measurements were performed in each animal using right and left DRGs. The tissues were frozen quickly on dry ice and stored at $-80^{\circ} \mathrm{C}$ until NGF extraction. The samples were homogenized in buffer $(100 \mu \mathrm{l})$ containing Trisma $\mathrm{HCl}(2.66 \%)$, Trisma base (0.985\%), phenylmethylsulfonyl fluoride $(0.5 \mathrm{~mm})$, leupeptin $(1 \mu \mathrm{M})$, pepstatin $\mathrm{A}(1 \mu \mathrm{M})$, and aprotinin $(0.3 \mu \mathrm{M})$. The homogenate was centrifuged at $10,000 \times g$ for $4 \mathrm{~min}$. The supernatant was diluted with $4 \mathrm{vol}$ of Dulbecco's PBS $\left(0.02 \% \mathrm{KCl}, 0.8 \% \mathrm{NaCl}, 0.02 \% \mathrm{KH}_{2} \mathrm{PO}_{4}, 0.115 \%\right.$ $\mathrm{Na}_{2} \mathrm{HPO}_{4}, 0.0133 \% \mathrm{CaCl}_{2} \cdot 2 \mathrm{H}_{2} \mathrm{O}, 0.01 \% \mathrm{MgCl}_{2} \cdot 6 \mathrm{H}_{2} \mathrm{O}, \mathrm{pH}$ 7.35). The samples were acidified by $10 \mathrm{~N} \mathrm{HCl}$ to $\mathrm{pH} 2.0-3.0$ for $15 \mathrm{~min}$ at room temperature and then neutralized by $10 \mathrm{~N} \mathrm{NaOH}$ to $\mathrm{pH} 7.5-8.0$ to promote the dissociation of NGF from receptors or binding proteins (Okragly and Haak-Frendscho, 1997). After acid treatment, the samples were stored in a deep freezer at $-80^{\circ} \mathrm{C}$ until assayed. The samples were assayed in triplicate in an antigen capture ELISA ( $\mathrm{E}_{\max }$ ImmunoAssay System; Promega, Madison, WI) according to the manufacturer's instructions. ELISA plates were read at $450 \mathrm{~nm}$ on an Elx800 microplate reader (BioTek Instruments, Winooski, VT).

Total protein concentration for the same samples was also determined with a protein assay kit (BCA Protein Assay kit; Pierce, Rockford, IL). All tissue NGF values were standardized by tissue protein levels and expressed as picograms per microgram of total protein.

\section{Experiment 2: electrophysiological properties of bladder afferent} neurons after NGF treatment

In the separate group of animals, patch-clamp recordings were performed in dye-labeled bladder afferent neurons obtained from vehicletreated rats and rats treated with NGF for 1 or 2 weeks. Intrathecal NGF or vehicle delivery through implanted intrathecal catheters were performed as described in experiment 1.

Dye labeling. The subpopulations of DRG neurons that innervate the urinary bladder were labeled by retrograde axonal transport of a fluorescent dye, Fast Blue (4\% w/v; EMS Chemie, Zürich, Switzerland) injected into the bladder wall (Yoshimura et al., 1994, 1998) at the same time that the NGF injection was started. The bladder was exposed by a midline lower abdominal incision and the dye was injected with a 29 -gauge needle at four to six sites (total volume of 20-30 $\mu \mathrm{l}$ ) on the dorsal surface of the bladder under halothane anesthesia. At each injection site, the needle was kept in place for 20-30 s, and any leakage of dye was removed by application of cotton swab. The injection site was then rinsed with saline and the abdominal incision was closed. We have previously demonstrated that dye labeling does not affect electrical properties of DRG neurons (Yoshimura et al., 1994).

Patch-clamp recordings. Isolated neurons were dissociated from DRGs with enzymatic and mechanical methods as described previously (Yoshimura et al., 1994, 1996, 2003) 1 or 2 weeks after the start of intrathecal NGF application. Briefly, L6 and S1 DRGs, which contain cell bodies of bladder afferents carried through the pelvic nerve, were dissected under halothane anesthesia, incubated in a bath for $25 \mathrm{~min}$ at $35^{\circ} \mathrm{C}$ with $5 \mathrm{ml}$ of DMEM (Sigma-Aldrich, St. Louis, MO) containing $0.3 \mathrm{mg} / \mathrm{ml}$ trypsin (type 3; Sigma-Aldrich), $1 \mathrm{mg} / \mathrm{ml}$ collagenase (type 1; Sigma-Aldrich), and $0.1 \mathrm{mg} / \mathrm{ml}$ deoxyribonuclease (type 4; Sigma-Aldrich). Trypsin inhibitor (type 2a; Sigma-Aldrich) was then added to neutralize the activity of trypsin. Individual DRG cell bodies were isolated by trituration and then plated on poly-L-lysine-coated $35 \mathrm{~mm}$ Petri dishes. Dye-labeled primary afferent neurons that innervate the urinary bladder were identified using an inverted phase contrast microscope (Nikon, Tokyo, Japan) with fluorescent attachments (UV-1A filter; excitation wave length, $365 \mathrm{~nm}$ ). Gigaohm-seal whole-cell recordings were performed at room temperature $\left(20-22^{\circ} \mathrm{C}\right)$ on each freshly dissociated labeled neuron in a culture dish, which usually contained two to five labeled cells among a 
few hundred unlabeled neurons. All recordings were performed with an Axopatch 200A patch-clamp amplifier (Molecular Devices, Union City, CA) within $12 \mathrm{~h}$ after dissociation, and data were acquired and analyzed by PCLAMP software (Molecular Devices). After the tissue removal, animals were killed by an overdose of pentobarbital (120 mg/kg, i.p.).

We first evaluated action potential characteristics and capsaicin sensitivity in bladder afferent neurons from vehicle-treated and NGF ( 1 or 2 week)-treated rats. The internal solution contained the following (in mM): $130 \mathrm{KCl}, 10 \mathrm{NaCl}, 1 \mathrm{CaCl}_{2}, 2 \mathrm{MgCl}_{2}, 9$ EGTA, 10 HEPES, $4 \mathrm{Mg}$ ATP, and 0.3 GTP (Tris salt) adjusted to $\mathrm{pH} 7.4$ with $\mathrm{KOH}$ (310 mOsm). Patch electrodes had resistances of 1-4 M $\Omega$ when filled with the internal solution. Neurons were superfused at a flow rate of $1.5 \mathrm{ml} / \mathrm{min}$ with an external solution containing $150 \mathrm{NaCl}, 5 \mathrm{KCl}, 2.5 \mathrm{CaCl}_{2}, 1 \mathrm{MgCl}_{2}, 10$ HEPES, and 10 D-glucose, adjusted to pH 7.4 with $\mathrm{NaOH}$ (340 mOsm). Durations of action potentials were measured at $50 \%$ of the spike amplitude. Thresholds for action potential activation were determined by injection of depolarizing current pulses in $10 \mathrm{pA}$ steps. Tetrodotoxin (TTX) was applied to neurons by superfusion in the external solution for $1 \mathrm{~min}$ to examine TTX sensitivity of action potentials, and then washed out for over $5 \mathrm{~min}$ with the external solution. In current-clamp recordings, data are presented from neurons that exhibited resting membrane potentials more negative than $-40 \mathrm{mV}$ and action potentials that overshot $0 \mathrm{mV}$.

After the evaluation of action potential characteristics, capsaicin sensitivity was evaluated by direct application of capsaicin $(1 \mu \mathrm{M})$ to the cells by pressure ejection (Picosplitzer; General Valve, Fairfield, NJ) through a glass pipette (10-20 $\mu \mathrm{m}$ tip diameter; $500 \mathrm{~ms}$ at $5-10 \mathrm{psi}$ ) in a voltageclamp mode with a holding potential at $-60 \mathrm{mV}$. Inward shift of holding currents was observed in capsaicin-sensitive cells. Capsaicin (SigmaAldrich) was dissolved in the normal external solution containing $10 \%$ alcohol and $10 \%$ Tween 80 at a concentration of $5 \mathrm{~mm}$, and then diluted in the external solution before experiments. No effects were detected by application of alcohol and Tween 80 in concentrations as high as $0.2 \%$.

After the evaluation of action potential characteristics and capsaicin sensitivity, bladder afferent neurons with TTX-resistant action potentials from vehicle-treated and NGF (2 week)-treated rats were divided into two groups and subjected to an investigation of the properties of either $\mathrm{K}^{+}$or $\mathrm{Na}^{+}$currents by switching the external solutions. For isolation of $\mathrm{K}^{+}$currents, neurons were superfused at a flow rate of $1.5 \mathrm{ml} / \mathrm{min}$ with an external solution containing the following (in mM): 150 choline-Cl, 5 $\mathrm{KOH}, 0.03 \mathrm{CaCl}_{2}, 10 \mathrm{HEPES}, 3 \mathrm{Mg}(\mathrm{OH})_{2}$, and $10 \mathrm{D}$-glucose adjusted to pH 7.4 with $\mathrm{HCl}$ that suppresses $\mathrm{Na}^{+}$and $\mathrm{Ca}^{2+}$ currents (Yoshimura and de Groat 1999; Yang et al., 2004). The peak amplitudes of the currents were measured and converted to $\mathrm{K}^{+}$conductances by means of the following equation: $G_{\mathrm{K}}=I_{\mathrm{K}} /\left(V-V_{\text {rev }}\right)$, where $G_{\mathrm{K}}$ is the $\mathrm{K}^{+}$conductance, $I_{\mathrm{K}}$ is the $\mathrm{K}^{+}$current, $V$ is the test command potential, and $V_{\text {rev }}$ is the reversal potential for the $\mathrm{K}^{+}$current. To correct the $\mathrm{K}^{+}$conductance for cell size, the $\mathrm{K}^{+}$conductances for each cell were normalized with respect to cell membrane capacitances that were obtained by reading the value for whole-cell input capacitance neutralization directly from the amplifier.

For isolation of $\mathrm{Na}^{+}$currents, neurons were superfused at a flow rate of $1.5 \mathrm{ml} / \mathrm{min}$ with an external solution containing the following (in $\mathrm{mm}$ ): $50 \mathrm{NaCl}, 90$ TEA-Cl, 5 4-aminopyridine, $0.03 \mathrm{CaCl}_{2}, 10 \mathrm{HEPES}, 10$ $\mathrm{MgCl}_{2}$, and 10 D-glucose adjusted to $\mathrm{pH} 7.4$ with TEA-OH (340 mOsm/ $\mathrm{L}$ ). The peak amplitudes of the currents were measured and converted to $\mathrm{Na}^{+}$conductances by means of the following equation: $G_{\mathrm{Na}}=I_{\mathrm{Na}} /(\mathrm{V}-$ $\left.V_{\text {rev }}\right)$, where $G_{\mathrm{Na}}$ is the $\mathrm{Na}^{+}$conductance, $I_{\mathrm{Na}}$ is the $\mathrm{Na}^{+}$current, $V$ is the test command potential, and $V_{\text {rev }}$ is the reversal potential for the $\mathrm{Na}^{+}$ current. To correct the $\mathrm{Na}^{+}$conductance for cell size, the $\mathrm{Na}^{+}$conductances for each cell were normalized with respect to cell membrane capacitances. Steady-state activation and inactivation data for $\mathrm{Na}^{+}$or $\mathrm{K}^{+}$ currents were fitted by the modified Boltzmann equation: $G / G_{\max }=$ $1 /\left[1+\exp \left(V_{\mathrm{h}}-V\right) / k\right]$, where $G$ is the conductance, $G_{\max }$ is the fitted maximal conductance, $V_{\mathrm{h}}$ is the membrane potential for half-activation and inactivation, $V$ is the test command potential, and $k$ is the slope factor. In voltage-clamp recordings, the filter was set to $-3 \mathrm{~dB}$ at 2000 $\mathrm{Hz}$. Leak currents were subtracted by $\mathrm{P} / 4$ pulse protocol, and the series resistance was compensated by $60-80 \%$.

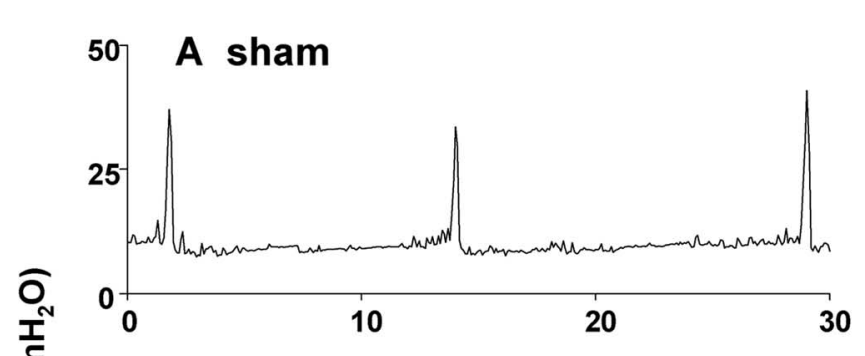

B NGF 1W

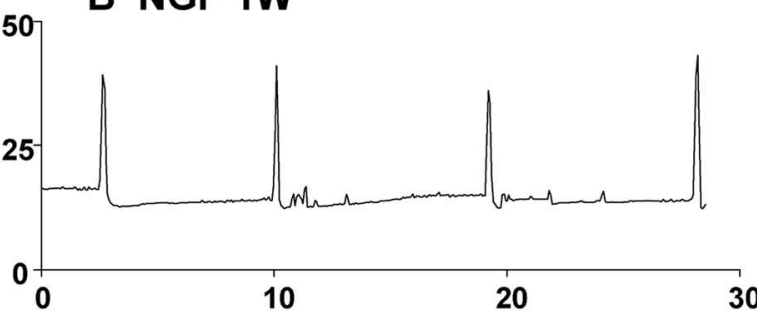

C NGF 2W

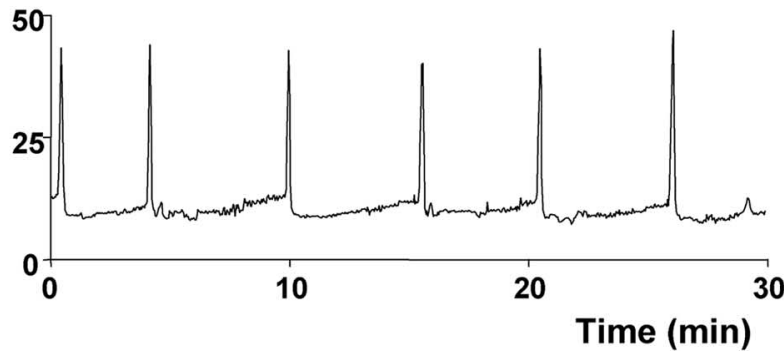

Figure 1. Representative traces of cystometry. $\boldsymbol{A}$, Vehicle-treated rat (sham). $\boldsymbol{B}$, NGF-treated rat for 1 week (NGF 1W). C, NGF-treated rat for 2 weeks (NGF 2W). Note a time-dependent reduction in intercontraction intervals in NGF-treated rats.

\section{Statistical analysis}

All values are expressed as mean $\pm \mathrm{SE}$. The Mann-Whitney $U$ test and Student's $t$ test were used to determine significance. For all statistical tests, $p<0.05$ was considered significant.

\section{Results}

\section{Cystometry}

In cystometry under an awake condition, treatment with NGF for 1 and 2 weeks induced bladder overactivity in a time-dependent manner as revealed by significant decreases in ICIs by 36 and $61 \%$, respectively, compared with vehicle-treated rats (ICI, $769 \pm$ 78 s) (Figs. 1, 2). VV was also significantly decreased by 21 and $61 \%$ from the control value $(0.68 \pm 0.13 \mathrm{ml})$ in vehicle-treated animals after 1 and 2 weeks of NGF treatment, respectively (Fig. 2). MVP, BP, and PT were not significantly altered by NGF treatment (Table 1). Postvoid residual volume was negligible in both vehicle-treated and NGF-treated animals. In addition, no discernible nonvoiding contractions that are defined as contractile activity without voiding during the filling phase were observed in NGF-treated animals.

\section{NGF levels in DRGs}

After 1 or 2 weeks of intrathecal NGF application at the level of L6-S1 spinal cord, NGF levels in L6 DRGs were significantly increased to $44.0 \pm 4.1$ and $49.4 \pm 5.2 \mathrm{pg} / \mu \mathrm{g}$, respectively, compared with untreated $(27.8 \pm 2.6 \mathrm{pg} / \mu \mathrm{g})$ or vehicle-treated rats $(30.8 \pm 2.6 \mathrm{pg} / \mu \mathrm{g})$ (Fig. 3). Similar increases in NGF levels in S1 DRGs $(42.0 \pm 2.3$ and $45.2 \pm 2.9 \mathrm{pg} / \mu \mathrm{g})$ were also detected after 

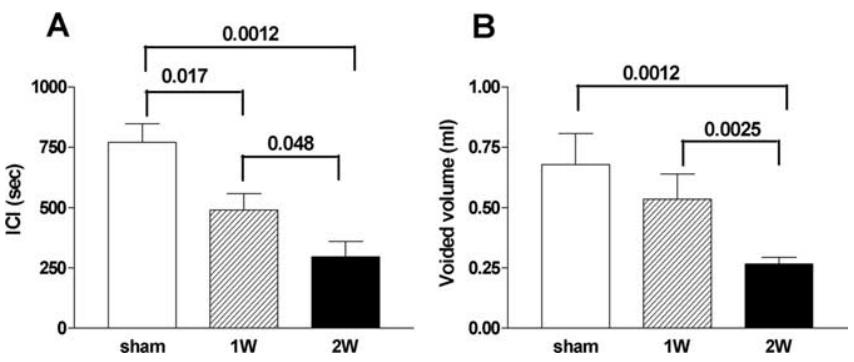

Figure 2. The effects of NGF treatment on cystometric parameters. $\boldsymbol{A}$, Averaged ICls in vehicle-treated rats (sham) ( $n=7)$ and rats treated with NGF for 1 week $(1 \mathrm{~W})(n=5)$ or 2 weeks $(2 \mathrm{~W})(n=7)$. $\boldsymbol{B}$, Averaged voided volume in vehicle-treated rats (sham) $(n=7)$ and rats treated with NGF for $1(1 \mathrm{~W})(n=5)$ or 2 weeks $(2 W)(n=7)$. Values of $p<0.05$ compared with the sham group are indicated. Error bars indicate $S E$.

Table 1. Cystometric parameters in vehicle-treated and NGF-treated rats

\begin{tabular}{lccc}
\hline & \multicolumn{3}{l}{ NGF } \\
\cline { 3 - 4 } & Vehicle & 1 week & 2 week \\
\hline No. of animals & 7 & 5 & 7 \\
Maximal voiding pressure $\left(\mathrm{cmH}_{2} \mathrm{O}\right)$ & $38.0 \pm 2.8$ & $38.0 \pm 3.0$ & $37.6 \pm 3.1$ \\
Pressure threshold $\left(\mathrm{cmH}_{2} \mathrm{O}\right)$ & $9.6 \pm 0.58$ & $11 \pm 1.3$ & $9.7 \pm 0.68$ \\
Baseline pressure $\left(\mathrm{CmH}_{2} \mathrm{O}\right)$ & $5.9 \pm 0.6$ & $7.2 \pm 2.2$ & $6.6 \pm 0.4$ \\
\hline
\end{tabular}

1 and 2 weeks of NGF application, respectively, compared with untreated $(31.4 \pm 7.1 \mathrm{pg} / \mu \mathrm{g})$ or in vehicle-treated rats $(35.2 \pm$ $2.2 \mathrm{pg} / \mu \mathrm{g})$. There was no significant difference in NGF levels in L6 or S1 DRGs after 1 and 2 weeks of NGF treatment, indicating that NGF delivery to DRGs plateaued in 1 week and that the increased NGF levels were maintained for up to 2 weeks. In contrast, NGF levels in L5 DRGs $(29.1 \pm 7.8 \mathrm{pg} / \mu \mathrm{g}$ in untreated DRGs) were not significantly different in untreated, vehicle- and NGF treated rats ( 1 and 2 weeks), indicating that NGF intrathecally delivered at the L6-S1 spinal cord level was concentrated at the site of injection.

\section{Action potential and passive membrane characteristics}

In vehicle-treated rats, 30 of 42 bladder afferent neurons (71\%) exhibited long-duration $(8.1 \pm 0.5 \mathrm{~ms})$ action potentials that were resistant to $1 \mu \mathrm{M}$ TTX (Fig. $4 A$, Table 2). The mean threshold for TTX-resistant spike activation was $-21.1 \pm 1.1 \mathrm{mV}$, and the average size of TTX-resistant neurons was $24.1 \pm 1.6 \mu \mathrm{m}$ in diameter with the mean cell input capacitance of $30.4 \pm 1.6 \mathrm{pF}$ (Table 2). In 30 bladder afferent neurons with TTX-resistant action potentials, 93\% (28 cells) of neurons exhibited inward currents (average peak amplitude, $2.62 \pm 0.25 \mathrm{nA}$; range, $0.8-3.6$ $\mathrm{nA}$ ) in response to $1 \mu \mathrm{M}$ capsaicin application. In addition, TTXresistant bladder afferent neurons from vehicle-treated rats usually exhibited a phasic pattern of firing ( $1.3 \pm 0.2$ spikes $)$ during a prolonged membrane depolarization (600 ms duration) when the current intensity was set to the value just above the threshold for spike activation with $10 \mathrm{~ms}$ pulses (Fig. 4, Table 2).

The remaining 12 bladder afferent neurons that exhibited TTX-sensitive action potentials from vehicle-treated rats were significantly larger in size (diameter, $34.1 \pm 1.7 \mu \mathrm{m})$ and had shorter duration $(5.2 \pm 0.7 \mathrm{~ms})$ action potentials that were activated at lower thresholds $(-29.3 \pm 1.5 \mathrm{mV})$ than TTX-resistant neurons (Table 2). Only one of these neurons was sensitive to capsaicin. TTX-sensitive bladder afferent neurons from vehicletreated rats usually exhibited a tonic pattern of firing $(11.3 \pm 2.1$ spikes) during membrane depolarization (600 ms duration) (Table 2). These results were similar to those previously obtained in bladder afferent neurons in untreated normal rats (Yoshimura et al., 1996, 2003; Yoshimura and de Groat, 1999).

After 1 and 2 weeks of intrathecal NGF application, a similar proportion [ 34 of 47 neurons ( $72 \%$ ) and 42 of 58 neurons (72\%), respectively] of bladder afferent neurons exhibited TTX-resistant action potentials whose durations $(7.5 \pm 0.6$ and $6.9 \pm 0.4 \mathrm{~ms})$ were slightly, but not significantly, shorter than those in vehicletreated bladder afferent neurons (Fig. 4, Table 2). In addition, the majority (93-94\%) of TTX-resistant bladder afferent neurons from NGF-treated rats were sensitive to capsaicin ( $1 \mu \mathrm{M})$, as observed in vehicle-treated animals (Table 2 ). The average peak amplitude of capsaicin-induced currents $(2.72 \pm 0.22$ and $2.88 \pm$ $0.14 \mathrm{nA}$, respectively) in TTX-resistant bladder afferent neurons from 1 and 2 week NGF-treated rats did not differ from that in the neurons from vehicle-treated rats. However, the mean threshold for spike activation in TTX-resistant bladder afferent neurons from NGF-treated rats ( 1 and 2 weeks) was significantly $(p<$ 0.05 and $p<0.01)$ lower $(-25.4 \pm 1.6$ and $-28.2 \pm 1.7 \mathrm{mV}$, respectively) than in TTX-resistant bladder neurons from vehicle-treated animals (Fig. 4, Table 2). Sustained membrane depolarizations (600 ms duration) produced three or more action potentials (i.e., a tonic pattern of firing) in 19 of $34(56 \%)$ and 32 of 42 bladder neurons (76\%) exhibiting TTX-resistant spikes from 1 and 2 week NGF-treated rats, respectively. The average number of action potentials in 34 and 42 TTX-resistant neurons from 1 and 2 week NGF-treated rats was significantly increased in a time-dependent manner to $6.7 \pm 2.2(p<0.05)$ and $11.6 \pm 1.8$ spikes $(p<0.01)$ during $600 \mathrm{~ms}$ depolarizing current pulses, respectively, compared with TTX-resistant neurons from vehicle-treated rats (Fig. 4, Table 2). In addition, the mean diameter $(29.9 \pm 1.5 \mu \mathrm{m})$ and cell input capacitance $(42.8 \pm 3.4 \mathrm{pF})$ of TTX-resistant bladder neurons in 2 week NGFtreated rats were significantly $(p<0.01)$ greater than in vehicletreated rats. Increases in cell size and capacitance $(26.8 \pm 1.4 \mu \mathrm{m}$ and $34.1 \pm 2.5 \mathrm{pF}$, respectively) in 1 week NGF-treated rats were not significantly different from vehicle-treated neurons.

NGF treatment did not affect action potential characteristics in bladder afferent neurons with TTX-sensitive spikes because spike thresholds and the number of spikes during a long duration of depolarizing current pulses were not significantly different between vehicle-treated and NGF-treated rats (Table 2).

\section{$\mathrm{K}^{+}$currents in bladder afferent neurons}

Because intrathecal NGF application induced hyperexcitability of bladder afferent neurons with TTX-resistant spikes, but not those with TTX-sensitive spikes, an additional investigation was performed on changes in the properties of voltage-gated $\mathrm{K}^{+}$currents in bladder neurons with TTX-resistant spikes from vehicletreated rats and rats treated with NGF for 2 weeks. These experiments were performed after the characterization of action potential properties and capsaicin sensitivity in each neuron. To isolate $\mathrm{K}^{+}$currents, $\mathrm{Na}^{+}$in the external solution was replaced with equimolar choline and $\mathrm{Ca}^{2+}$ was reduced to $0.03 \mathrm{~mm}$ to suppress $\mathrm{Na}^{+}$and $\mathrm{Ca}^{2+}$ currents (Elliott and Elliott, 1993). The reduced extracellular $\mathrm{Ca}^{2+}$ would also be expected to suppress $\mathrm{Ca}^{2+}$-activated $\mathrm{K}^{+}$current. The outward currents recorded under these conditions appeared to be carried by $\mathrm{K}^{+}$ions because the outward currents were almost completely blocked by inclusion of 4-aminopyridine ( $5 \mathrm{~mm})$ and tetraethylammonium (50 $\mathrm{mm})$ in the external solution with a residual outward current of $38.2 \pm 4.6 \mathrm{pA}(n=6)$. The reversal potential of the instantaneous tail currents under these conditions was close $(-78 \mathrm{mV})$ to the 

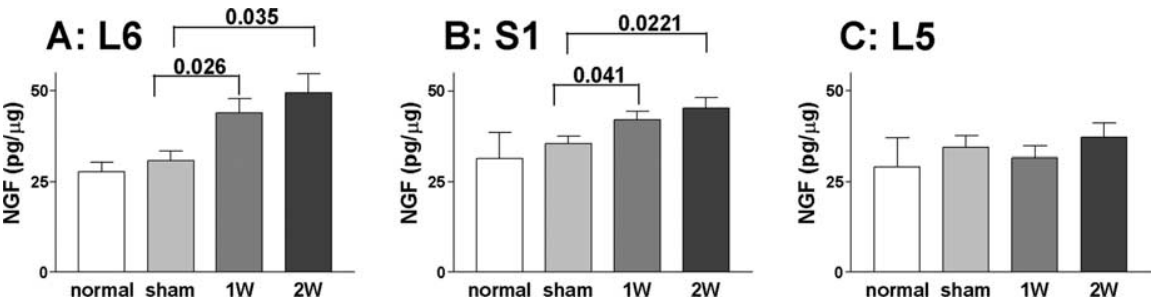

Figure 3. ELISA measurements of NGF in DRGs in untreated (normal), vehicle-treated (sham), and NGF-treated rats [1 week (1W) or 2 weeks (2W)]. A, L6 DRGs. B, S1 DRGs. C, L5 DRGs. NGF values (in picograms) were standardized by tissue protein levels (in micrograms) and expressed as picograms per microgram of total protein. Values of $p<0.05$ compared with the sham group are indicated. Error bars indicate SE.
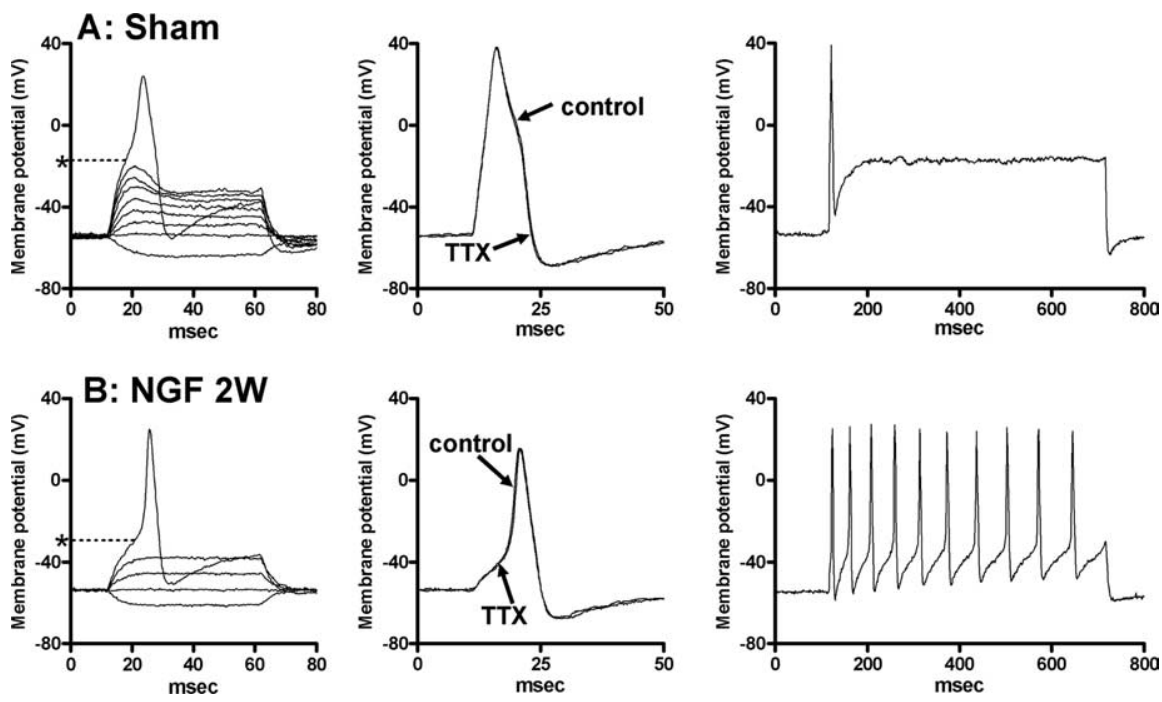

Figure 4. Characteristics of action potentials in capsaicin-sensitive bladder afferent neurons with TTX-resistant action potentials. $A$, Vehicle-treated rat (sham). $\boldsymbol{B}$, Rat treated with NGF for 2 weeks (NGF 2W). The left panels are voltage responses and action potentials evoked by $60 \mathrm{~ms}$ depolarizing current pulses injected through the patch pipette in current-clamp conditions. Asterisks with dashed lines indicate the thresholds for spike activation $(-18 \mathrm{mV}$ in $\boldsymbol{A}$ and $-31 \mathrm{mV}$ in $\boldsymbol{B})$. The middle panels show the effects of TTX application (1 $\mu \mathrm{M}$ ) on action potentials. The right panels show firing patterns during membrane depolarization $(600 \mathrm{~ms}$ duration). The current intensity was set to the threshold value for inducing single spikes with $10 \mathrm{~ms}$ current pulses as indicated in middle panels.

theoretical reversal potential for $\mathrm{K}^{+}$ions calculated by Nernst equation $(-82 \mathrm{mV})$ (data not shown).

Previous studies have demonstrated that delayed rectifier $\left(\mathrm{K}_{\mathrm{DR}}\right)$ and slowly decaying A-type $\mathrm{K}^{+}\left(\right.$slow $\mathrm{K}_{\mathrm{A}}$ ) currents are two major types of voltage-gated $\mathrm{K}^{+}$currents expressed in smallsized, capsaicin-sensitive DRG neurons including bladder afferent neurons that exhibited TTX-resistant action potentials with inflections on the repolarization phase (Gold et al., 1996; Yoshimura et al., 1996, 1999). Because slow $K_{A}$ currents can be activated by depolarizing voltage steps from hyperpolarized membrane potentials and inactivated almost completely when the membrane potential is maintained at a depolarized level more than $-40 \mathrm{mV}$ (Hall et al., 1994; Yoshimura et al., 1996, 1999), an estimate of the slow $\mathrm{K}_{\mathrm{A}}$ current was obtained by the difference in the currents activated by depolarizing voltage pulses from a holding potential of $-40 \mathrm{mV}$ and from a hyperpolarized holding potential of $-120 \mathrm{mV}$. Figure 5 shows the superimposed outward $\mathrm{K}^{+}$currents induced by depolarizing voltage pulses from two different holding potentials $(-120$ and $-40 \mathrm{mV})$ in a bladder afferent neuron with TTX-resistant spikes from a vehicle-treated rat. Whereas sustained $\mathrm{K}_{\mathrm{DR}}$ currents were recorded from a holding potential of $-40 \mathrm{mV}$ (Fig. $5 B$ ), additional slow $\mathrm{K}_{\mathrm{A}}$ currents were only activated when the holding potential was hyperpolar- ized to $-120 \mathrm{mV}$ (Fig. 5A). As previously reported (McFarlane and Cooper, 1991; Akins and McCleskey, 1993; Hall et al., 1994; Gold et al., 1996; Yoshimura et al., 1996), slow $K_{A}$ currents were activated at lower thresholds than $\mathrm{K}_{\mathrm{DR}}$ currents (Fig. $5 D, E)$.

The magnitude of slow $\mathrm{K}_{\mathrm{A}}$ currents evoked by depolarization to $0 \mathrm{mV}$, which was calculated from the difference in $\mathrm{K}^{+}$ currents activated from holding potentials of -40 and $-120 \mathrm{mV}$ (Fig. $5 C$ ), was significantly $(p<0.01)$ smaller in NGF-treated bladder afferent neurons $(0.52 \pm 0.07 \mathrm{nS} /$ $\mathrm{pF} ; n=20)$ than in vehicle-treated bladder afferent neurons $(1.09 \pm 0.16 \mathrm{nS} / \mathrm{pF} ; n=$ 15) (Fig. 5E, Table 3). Inactivation and activation characteristics of slow $\mathrm{K}_{\mathrm{A}}$ currents were not different in vehicle-treated and NGF-treated bladder afferent neurons (Fig. 6). In contrast, the magnitude of the maximal sustained $\mathrm{K}_{\mathrm{DR}}$ currents evoked by depolarization to $20 \mathrm{mV}$ from a holding potential of $-40 \mathrm{mV}$ was not altered in NGF-treated bladder afferent neurons $(1.19 \pm 0.09 \mathrm{nS} / \mathrm{pF})$ compared with $\mathrm{K}_{\mathrm{DR}}$ currents in vehicle-treated neurons $(1.33 \pm 0.13 \mathrm{nS} / \mathrm{pF}$ ) (Fig. 5D, Table 3). These results indicate that after 2 weeks of NGF treatment, the current density of slow $\mathrm{K}_{\mathrm{A}}$ currents was decreased, whereas the density of $\mathrm{K}_{\mathrm{DR}}$ currents was unchanged in hyperexcitable bladder afferent neurons with TTX-resistant spikes.

\section{$\mathrm{Na}^{+}$currents in bladder afferent neurons}

Voltage-gated $\mathrm{Na}^{+}$currents were investigated in another group of bladder afferent neurons with TTX-resistant spikes obtained from rats treated with NGF for 2 weeks, and compared with those from vehicle-treated rats. These experiments were performed after the characterization of action potential properties and capsaicin sensitivity in each neuron. To isolate $\mathrm{Na}^{+}$currents, 4-aminopyridine $(5 \mathrm{~mm})$ and tetraethylammonium (90 $\mathrm{mm})$ were added in the external solution and $\mathrm{Ca}^{2+}$ was reduced to 0.03 $\mathrm{mM}$ to suppress $\mathrm{K}^{+}$and $\mathrm{Ca}^{2+}$ currents. Under these conditions, the inward currents elicited by depolarizing pulses from a holding potential of $-60 \mathrm{mV}$ were almost completely eliminated by the equimolar substitution of $\mathrm{Na}^{+}$ions by choline with a residual outward current of $58.6 \pm 6.6 \mathrm{pA}(n=7)$, indicating that inward currents were carried by $\mathrm{Na}^{+}$ions and that contamination by outward $\mathrm{K}^{+}$currents was minimal (data not shown).

As previously reported, bladder afferent neurons with TTXresistant spikes predominantly exhibited TTX-resistant $\mathrm{Na}^{+}$currents when activated from holding potentials of $-60 \mathrm{mV}$, which approximated the resting membrane potential (Fig. 7) (Yoshimura et al., 1996; Yoshimura and de Groat, 1997). As shown in Figure $7 C$, extracellular TTX $(1 \mu \mathrm{M})$ application only slightly ( $7.4 \pm 2.9 \%$; range, $0-15 \%)$ suppressed $\mathrm{Na}^{+}$currents elicited by depolarizing pulses to $10 \mathrm{mV}$ from a holding potential of -60 $\mathrm{mV}$ in both vehicle-treated $(n=15)$ and NGF-treated neurons $(n=20)$. However, TTX-sensitive $\mathrm{Na}^{+}$currents became more 
Table 2. Membrane characteristics of bladder afferent neurons in vehicle-treated and NGF-treated rats

\begin{tabular}{|c|c|c|c|}
\hline & & NGF & \\
\hline & Vehicle & 1 week & 2 week \\
\hline Neurons with TTX-resistan & & & \\
\hline No. of cells & 30 & 34 & 42 \\
\hline Diameter $(\mu \mathrm{m})$ & $24.1 \pm 1.6$ & $26.8 \pm 1.4$ & $29.9 \pm 1.5^{*}$ \\
\hline Input capacitance (pF) & $30.4 \pm 1.6$ & $34.1 \pm 2.5$ & $42.8 \pm 3.4^{* *}$ \\
\hline $\operatorname{RMP}(\mathrm{mV})$ & $-54.5 \pm 2.3$ & $-54.0 \pm 2.1$ & $-53.5 \pm 1.8$ \\
\hline Spike threshold (mV) & $-21.1 \pm 1.1$ & $-25.4 \pm 1.6^{*}$ & $-28.1 \pm 1.7^{* * *}$ \\
\hline Spike duration (ms) & $8.1 \pm 0.5$ & $7.51 \pm 0.6$ & $6.9 \pm 0.4$ \\
\hline №. of spikes (600 ms & & & \\
\hline depolarization) & $1.3 \pm 0.2$ & $7.7 \pm 2.2^{*}$ & $11.6 \pm 1.8^{* *}$ \\
\hline Capsaicin sensitivity & $28 / 30(93 \%)$ & $32 / 34(94 \%)$ & $39 / 42(93 \%)$ \\
\hline Neurons with TTX-sensitiv & & & \\
\hline No. of cells & 12 & 13 & 16 \\
\hline Diameter $(\mu \mathrm{m})$ & $34.1 \pm 1.7^{* *}$ & $35.2 \pm 1.5$ & $35.8 \pm 1.3$ \\
\hline Input capacitance (pF) & $47.2 \pm 2.2^{* *}$ & $46.2 \pm 2.8$ & $47.9 \pm 2.6$ \\
\hline $\operatorname{RMP}(\mathrm{mV})$ & $-57.2 \pm 2.9$ & $-58.0 \pm 2.1$ & $-56.9 \pm 2.6$ \\
\hline Spike threshold (mV) & $-29.3 \pm 1.5^{* *}$ & $-29.8 \pm 1.7$ & $-30.1 \pm 1.6$ \\
\hline Spike duration (ms) & $5.2 \pm 0.7^{*}$ & $5.0 \pm 0.5$ & $5.1 \pm 0.6$ \\
\hline No. of spikes ( $600 \mathrm{~ms}$ & & & \\
\hline depolarization) & $11.3 \pm 2.1^{* *}$ & $12.2 \pm 1.6$ & $12.3 \pm 1.8$ \\
\hline Capsaicin sensitivity & $1 / 12(8 \%)$ & $1 / 13(8 \%)$ & $2 / 16(12 \%)$ \\
\hline
\end{tabular}

RMP, Resting membrane potential.

${ }^{*} p<0.05,{ }^{*} p<0.01$ compared with the value in bladder afferent neurons with TTX-resistant spikes from vehicle-treated rats.
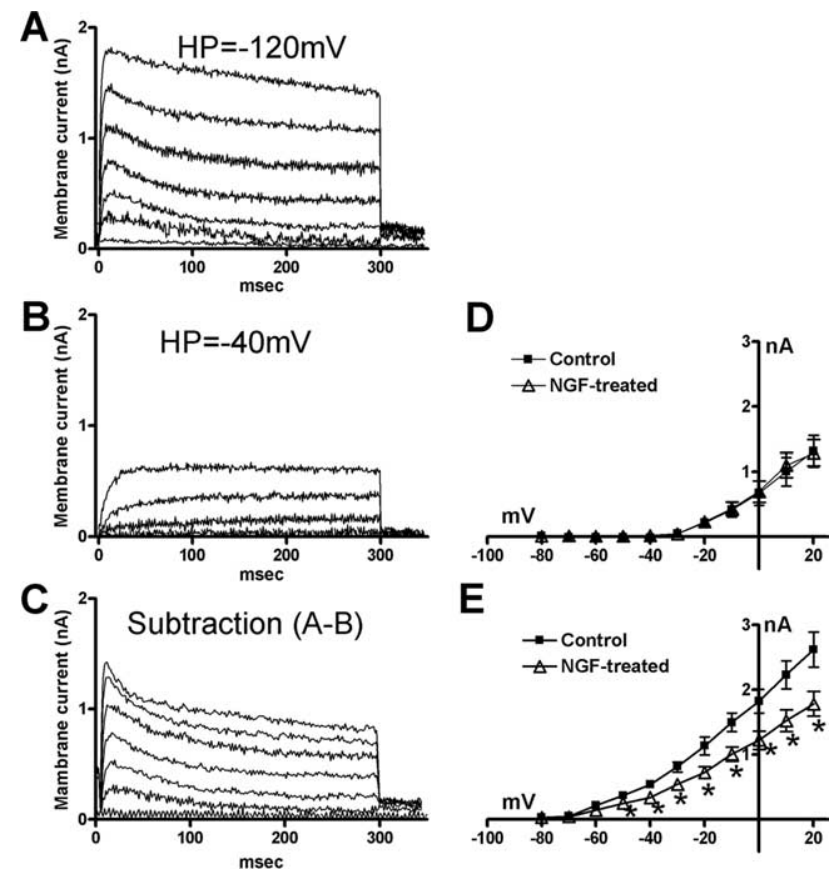

Figure 5. A, Superimposed $\mathrm{K}^{+}$currents activated by depolarizing voltage pulses from -80 to $0 \mathrm{mV}$ from a holding potential of $-120 \mathrm{mV}$ in a bladder afferent neuron with TTX-resistant spikes (diameter, $24 \mu \mathrm{m})$. B, Superimposed sustained delayer rectifier $\mathrm{K}^{+}$currents $\left(\mathrm{K}_{\mathrm{DR}}\right)$ activated by depolarizing voltage pulses from -80 to $0 \mathrm{mV}$ from holding potentials of $-40 \mathrm{mV}$ in the same neuron as in $\boldsymbol{A}$. $\boldsymbol{C}$, Isolated slowly inactivating transient $\mathrm{K}^{+}$currents $\left(\right.$slow $\left.\mathrm{K}_{\mathrm{A}}\right)$ obtained by the subtraction of currents in $\boldsymbol{A}$ and $\boldsymbol{B} . \boldsymbol{D}, \boldsymbol{E}, I-V$ relationships of $\mathrm{K}_{D R}$ currents $(\boldsymbol{B})$ and slow $\mathrm{K}_{\mathbf{A}}$ currents $(\boldsymbol{C})$, respectively, in vehicle (control) $(n=15)(\boldsymbol{\square})$ and NGF-treated $(n=20)$ $(\triangle)$ bladder afferent neurons. ${ }^{*} p<0.05$ compared with control neurons (Student's $t$ test). Error bars indicate SE.

apparent when the currents were elicited from hyperpolarized holding potentials at $-120 \mathrm{mV}$ (Fig. 7D). This is in accordance with previous findings that TTX-sensitive $\mathrm{Na}^{+}$currents in DRG neurons including bladder afferent neurons were fully activated
Table 3. $\mathrm{K}^{+}$and $\mathrm{Na}^{+}$current characteristics of bladder afferent neurons with TTXresistant spikes from vehicle-treated and NGF-treated rats

\begin{tabular}{lll}
\hline & Vehicle & NGF (2 weeks) \\
\hline $\mathrm{K}^{+}$currents & & \\
$\quad \mathrm{N}$. of cells & 15 & 20 \\
$\quad$ Input capacitance (pF) & $30.8 \pm 1.7$ & $42.5 \pm 2.7^{* *}$ \\
$\mathrm{~K}_{\mathrm{A}}$ conductance (at 0 mV) & & \\
$\quad$ Max (nS) & $33.6 \pm 4.4$ & $21.9 \pm 2.8^{*}$ \\
$\quad$ Normalized (nS/pF) & $1.09 \pm 0.16$ & $0.52 \pm 0.07^{* *}$ \\
$\mathrm{~K}_{\mathrm{DR}}$ conductance (at 20 mV) & & \\
$\quad$ Max (nS) & $39.9 \pm 3.8$ & $49.9 \pm 3.3$ \\
$\quad$ Normalized (nS/pF) & $1.33 \pm 0.13$ & $1.19 \pm 0.09$ \\
$\mathrm{Na}^{+}$currents & 15 & \\
$\quad$ No. of cells & $30.1 \pm 1.6$ & $43.1 \pm 2.6^{* *}$ \\
$\quad$ Input capacitance (pF) & & \\
$\quad \mathrm{TTX}-\mathrm{R} \mathrm{Na}{ }^{+}$conductance (at 10 mV) & $69.5 \pm 3.6$ & $97.4 \pm 3.9^{*}$ \\
$\quad$ Max (nS) & $2.31 \pm 0.12$ & $2.26 \pm 0.11$ \\
$\quad$ Normalized (nS/pF) & & \\
TTX-S Na ${ }^{+}$conductance (at 10 mV) & $42.3 \pm 4.1$ & $53.1 \pm 3.5$ \\
$\quad$ Max (nS) & $1.41 \pm 0.13$ & $1.23 \pm 0.10$ \\
$\quad$ Normalized (nS/pF) &
\end{tabular}

Max, Maximal conductance. Normalized, Conductance normalized with respect to cell input capacitance.

${ }^{*} p<0.05,{ }^{* *} p<0.01$ compared with the value in bladder afferent neurons with TTX-resistant spikes from vehicle-treated rats.
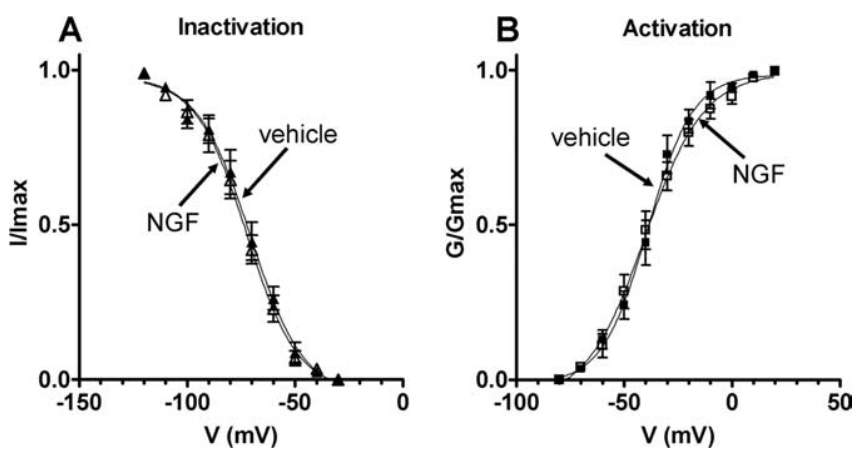

Figure 6. Steady-state activation and inactivation characteristics of slow $\mathrm{K}_{\mathrm{A}}$ currents in bladder afferent neurons with TTX-resistant spikes from vehicle-treated and NGF-treated rats (2 weeks). $\boldsymbol{A}$, Inactivation characteristics of slow $\mathrm{K}_{\mathrm{A}}$ currents in vehicle-treated animals $(n=15)$ $(\mathbf{\Delta})$ and NGF-treated animals $(n=20)(\triangle)$. Relative peak amplitude of slow $K_{A}$ currents normalized to the maximal amplitude of slow $K_{A}$ currents $\left(I / I_{\text {max }}\right)$ were plotted against membrane potentials. $V_{h}$ and $k$ obtained by fitting curves using the modified Boltzmann equation were $-70.7 \mathrm{mV}$ and -12.3 for vehicle-treated rats and $-72.4 \mathrm{mV}$ and -12.3 for NGF-treated rats. $B$, Activation characteristics of slow $K_{A}$ currents obtained in the neurons from vehicletreated animals $(n=15)(\square)$ and NGF-treated animals $(n=20)(\square)$. Slow $\mathrm{K}_{\mathrm{A}}$ conductances normalized to the maximal slow $K_{A}$ conductance $\left(G / G_{\max }\right)$ were plotted against membrane potentials. $V_{\mathrm{h}}$ and $k$ obtained by fitting curves using the modified Boltzmann equation were $-39.1 \mathrm{mV}$ and 10.5 for vehicle-treated rats and $-40.4 \mathrm{mV}$ and 13.6 for NGF-treated rats. Error bars indicate SE.

at holding potentials of $-120 \mathrm{mV}$, but greatly inactivated when holding membrane potentials were depolarized to a range of potentials between -60 and $-40 \mathrm{mV}$ (Elliott and Elliott, 1993; Yoshimura et al., 1996; Yoshimura and de Groat, 1997; McCleskey and Gold, 1999). Thus, we evaluated the magnitude of TTXresistant and TTX-sensitive $\mathrm{Na}^{+}$currents by a comparison of $\mathrm{Na}^{+}$currents elicited from holding potentials of $-120 \mathrm{mV}$ before and after TTX application. Figure 7D shows the superimposed $\mathrm{Na}^{+}$currents induced by depolarizing pulses to $10 \mathrm{mV}$ from holding potentials of $-120 \mathrm{mV}$ in a bladder afferent neuron with TTX-resistant spikes from a vehicle-treated rat. The magnitude of TTX-sensitive $\mathrm{Na}^{+}$currents, which were calculated as the difference in $\mathrm{Na}^{+}$currents before and after TTX application (Fig. $7 D$ ), were compared between vehicle-treated and 2 week NGF- 
A
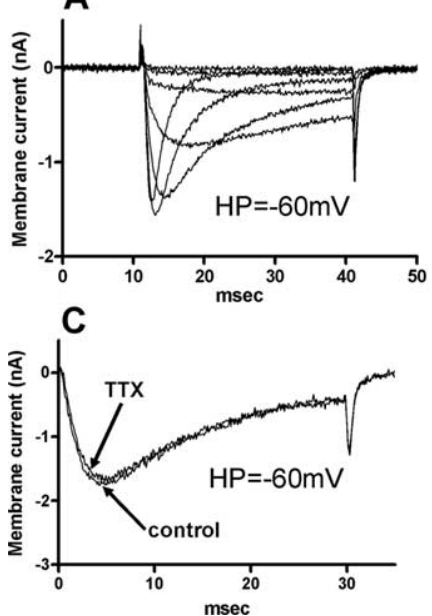

B
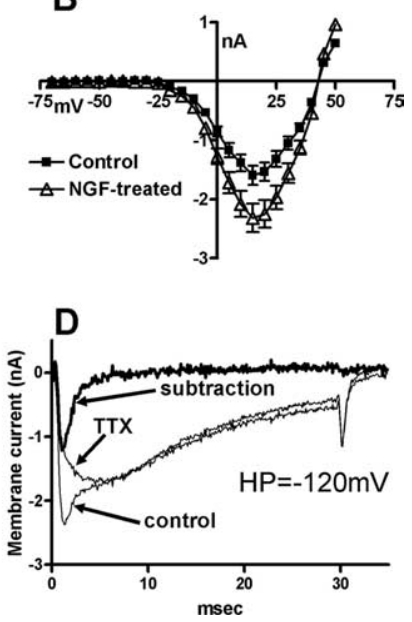

Figure 7. $A$, Superimposed traces of $\mathrm{Na}^{+}$currents elicited by depolarizing voltage steps from a holding potential of $-60 \mathrm{mV}$ in a bladder afferent neuron with TTX-resistant spikes from a vehicle-treated rat. $\boldsymbol{B}, I-V$ relationships of $\mathrm{Na}{ }^{+}$currents in vehicle (control) $(n=15)(\square)$ and NGF-treated $(n=20)(\triangle)$ bladder afferent neurons. Current amplitudes at -20 to $+35 \mathrm{mV}$ in NGF-treated neurons are significantly $(p<0.05)$ larger compared with control neurons (Student's $t$ test). Error bars indicate SE. C, Superimposed traces of $\mathrm{Na}^{+}$currents elicited by a depolarizing voltage step to $10 \mathrm{mV}$ from the holding potential of $-60 \mathrm{mV}$ in a bladder afferent neuron with TTX-resistant spikes from a NGF-treated rat before (control) and after $1 \mu \mathrm{M}$ TTX application (TTX). D, Superimposed traces of $\mathrm{Na}^{+}$currents elicited by a depolarizing voltage step to $10 \mathrm{mV}$ from the holding potential of $-120 \mathrm{mV}$ in the same neuron as in $C$ before (control) and after $1 \mu \mathrm{M}$ TTX application (TTX). The TTX-sensitive component of $\mathrm{Na}^{+}$currents obtained by the subtraction of currents before and after TTX application is indicated by a thick line (subtraction). Note that TTX-sensitive $\mathrm{Na}^{+}$currents were negligible when activated from the holding potential of $-60 \mathrm{mV}(\mathbf{C})$, whereas TTX-sensitive $\mathrm{Na}^{+}$currents became apparent when activated from the holding potential of $-120 \mathrm{mV}(\boldsymbol{D})$.

treated neurons. The peak amplitude of TTX-resistant $\mathrm{Na}^{+}$currents in NGF-treated neurons was significantly greater $(p<$ 0.05) at depolarizing pulses ranging from -20 to $35 \mathrm{mV}$ (Fig. $7 B$ ), and the calculated maximal TTX-resistant $\mathrm{Na}^{+}$conductance at $10 \mathrm{mV}$ in NGF-treated neurons was also significantly $(p<0.01)$ larger (97.4 \pm 3.9 vs $69.5 \pm 3.6 \mathrm{nS})$ compared with vehicletreated neurons (Table 3 ). However, when the conductance values were normalized with respect to cell membrane capacitance that was increased after NGF application, the density of TTXresistant $\mathrm{Na}^{+}$currents in vehicle-treated and NGF-treated neurons was not significantly different $(2.31 \pm 0.12$ vs $2.26 \pm 0.11$ $\mathrm{nS} / \mathrm{pF}$ ) (Table 3). Inactivation and activation characteristics of TTX-resistant $\mathrm{Na}^{+}$currents were not different in vehicle-treated and NGF-treated bladder afferent neurons (Fig. 8). In addition, the maximal $(42.3 \pm 4.1$ vs $53.1 \pm 3.5 \mathrm{nS} / \mathrm{pF})$ and normalized conductance $(1.41 \pm 0.13$ vs $1.23 \pm 0.10 \mathrm{nS} / \mathrm{pF})$ of TTX-sensitive $\mathrm{Na}^{+}$currents at $10 \mathrm{mV}$ did not significantly differ in vehicletreated and NGF-treated bladder afferent neurons (Table 3). These results indicate that, after 2 weeks of NGF treatment, the current density of TTX-resistant $\mathrm{Na}^{+}$channels was not significantly altered, whereas the total current amplitude of the currents was increased as cell hypertrophy occurred in bladder afferent neurons with TTX-resistant spikes.

\section{Discussion}

The results in the present study indicate that intrathecal NGF delivery for up to 2 weeks at the level of L6-S1 spinal cord, which increases NGF levels in L6-S1 DRGs, can time-dependently induce bladder overactivity and hyperexcitability of presumed C-fiber bladder afferent neurons with TTX-resistant action po-
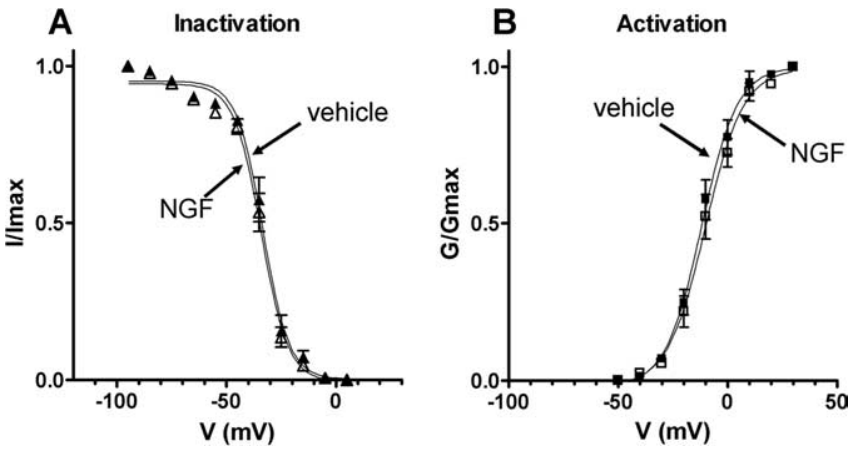

Figure 8. Steady-state activation and inactivation characteristics of TTX-resistant $\mathrm{Na}{ }^{+}$currents in bladder afferent neurons with TTX-resistant spikes from vehicle-treated and NGFtreated rats (2 weeks). $\boldsymbol{A}$, Inactivation characteristics of TTX-resistant $\mathrm{Na}^{+}$currents in vehicletreated animals $(n=15)(\mathbf{\Delta})$ and NGF-treated animals $(n=20)(\triangle)$. Peak amplitude of TTX-resistant $\mathrm{Na}^{+}$currents normalized to the maximal amplitude of TTX-resistant $\mathrm{Na}{ }^{+}$currents $\left(I / I_{\max }\right)$ were plotted against membrane potentials. $V_{\mathrm{h}}$ and $k$ obtained by fitting curves using the modified Boltzmann equation were $-33.3 \mathrm{mV}$ and -6.0 for vehicle-treated rats and $-34.1 \mathrm{mV}$ and -6.2 for NGF-treated rats. $\boldsymbol{B}$, Activation characteristics of TTX-resistant $\mathrm{Na}^{+}$ currents obtained in the neurons from vehicle-treated animals $(n=15)(\square)$ and NGF-treated animals $(n=20)(\square) . \mathrm{Na}^{+}$conductances normalized to the maximal $\mathrm{Na}^{+}$conductance $\left(G / G_{\max }\right)$ were plotted against membrane potentials. $V_{\mathrm{h}}$ and $k$ obtained by fitting curves using the modified Boltzmann equation were $-11.9 \mathrm{mV}$ and 8.2 for vehicle-treated rats and -10.1 $\mathrm{mV}$ and 8.7 for NGF-treated rats. Error bars indicate SE.

tentials. These effects are attributable at least in part to a reduction in slow $\mathrm{K}_{\mathrm{A}}$ current density.

Bladder overactivity and/or bladder pain under pathological conditions such as spinal cord injury or chronic cystitis is induced at least in part by hyperexcitable C-fibers in bladder afferent pathways (Chancellor and Yoshimura, 2002; Yoshimura et al., 2002). One possible mechanism underlying afferent sensitization under these pathological conditions involves increased production of neurotrophic factors such as NGF in the bladder and/or the spinal cord (Steers et al., 1991, 1996; Yoshimura, 1999; Vizzard, 2000; Seki et al., 2002, 2004; Hu et al., 2005). We also recently reported that NGF levels in lumbosacral DRGs were increased as NGF expression in the bladder and spinal cord was elevated in rats with spinal cord injury, and that immunoneutralization of NGF at the level of L6-S1 spinal cord segments significantly reduced NGF levels in L6-S1 DRGs and, at the same time, suppressed C-fiber-mediated bladder/urethral overactivity (Seki et al., 2002, 2004). Increased levels of NGF in L6-S1 DRGs (60$80 \%$ increase) after intrathecal NGF application (2 weeks) in this study was comparable with those obtained in rats with bladder overactivity induced by spinal cord injury (Seki et al., 2002).

Thus, it has been proposed that an increase of NGF in the bladder and/or spinal cord, and increased transport of NGF to sensory neurons may contribute to the functional changes in bladder afferent pathways under bladder pain and overactive conditions (Steers et al., 1991, 1996; Yoshimura, 1999; Vizzard, 2000; Dupont et al., 2001; Lamb et al., 2004; Hu et al., 2005). The present study provided for the first time direct evidence for this assumption because increased NGF levels in lumbosacral DRGs after intrathecal NGF delivery resulted in similar time-dependent progression of hyperexcitability of bladder afferent neurons and bladder overactivity. In addition, although in the present study intrathecal NGF treatment resulted in bladder overactivity as evidenced by a reduction in ICI, we did not observe detrusor overactivity defined as small contractile activity without voiding during the filling phase in NGF-treated rats, which is usually seen in spinal cord-injured rats. Because chronic spinal cord injury in- 
creases NGF levels not only in the spinal cord but also in the bladder (Seki et al., 2002), it is possible that increased NGF levels in the bladder and subsequent peripheral sensitization of $\mathrm{C}$-fibers might contribute to the emergence of nonvoiding bladder contractions (Yoshimura et al., 1999).

Our previous studies revealed that the majority of bladder afferent neurons exhibit TTX-resistant $\mathrm{Na}^{+}$currents and action potentials, and are capsaicin-sensitive (Yoshimura et al., 1996; Yoshimura, 1999; Yoshimura and de Groat, 1999). In addition, the majority ( $>95 \%$ ) of capsaicin-sensitive bladder afferent neurons from normal rats were the C-fiber type (unmyelinated) that did not stain with antibodies for the $200 \mathrm{kDa}$ subunit of neurofilament, whereas only a small proportion (5\%) of neurofilament-positive, myelinated A $\delta$-fiber bladder afferent neurons are sensitive to capsaicin (Yoshimura et al., 1998). Thus, it is likely that the majority of bladder afferent neurons that predominantly express TTX-resistant $\mathrm{Na}^{+}$currents are capsaicinsensitive C-fiber neurons.

Voltage-gated $\mathrm{K}^{+}$currents in sensory neurons are divided into two major categories [i.e., sustained delayed rectifier-type $\left(\mathrm{K}_{\mathrm{DR}}\right)$ and transient A-type $\mathrm{K}^{+}\left(\mathrm{K}_{\mathrm{A}}\right)$ currents] (Hall et al., 1994; Gold et al., 1996; Yoshimura et al., 1996; Yoshimura and de Groat, 1999; Yang et al., 2004). Transient $\mathrm{K}_{\mathrm{A}}$ currents in sensory neurons including DRG cells can be further subdivided into at least two different subtypes based on their inactivation kinetics (i.e., fast and slow $\mathrm{K}_{\mathrm{A}}$ currents) (McFarlane and Cooper, 1991; Akins and McCleskey, 1993; Gold et al., 1996; Everill et al., 1998: Everill and Kocsis, 1999). It has also been reported that the slow $\mathrm{K}_{\mathrm{A}}$ current, which was also termed the $\mathrm{K}_{\mathrm{D}}$ current by Everill et al. (1998), was preferentially expressed in small-sized DRG neurons that had TTX-resistant action potentials with inflections and responded to capsaicin (Gold et al., 1996; Yoshimura et al., 1996; Yoshimura and de Groat, 1999). Thus, it seems that $\mathrm{K}_{\mathrm{DR}}$ and slow $\mathrm{K}_{\mathrm{A}}$ currents are likely to be involved in modulating excitability in small-sized, nociceptive C-fiber DRG neurons. We also previously reported that chronic bladder inflammation resulted in a significant reduction in slow $\mathrm{K}_{\mathrm{A}}$ currents and increased excitability of capsaicin-sensitive, small-sized bladder afferent neurons and that application of 4-aminopyridine, a $\mathrm{K}_{\mathrm{A}}$ channel blocker, to control cells mimicked this effect as evidenced by changes in cell firing pattern from phasic to tonic (Yoshimura and de Groat, 1999). A similar reduction in $\mathrm{K}_{\mathrm{A}}$ currents was also demonstrated in hyperexcitable bladder afferent neurons from rats with chronic spinal cord injury (Yoshimura, 1999), in gastric afferent neurons from rats with gastric ulcers (Dang et al., 2004) and in intestinal afferent neurons from guinea pigs with ileitis (Stewart et al., 2003). Thus, the reduction in slow $K_{A}$ currents seems to be a key event resulting in hyperexcitability of $\mathrm{C}$-fiber afferent neurons innervating visceral organs. The present study further indicates that NGF is an important mediator to induce hyperexcitability of $\mathrm{C}$-fiber bladder afferent neurons attributable to the reduction in slow $\mathrm{K}_{\mathrm{A}}$ channel density.

In contrast to a significant reduction in $\mathrm{K}^{+}$currents, chronic NGF treatment increased the amplitude of TTX-resistant $\mathrm{Na}^{+}$ currents in C-fiber bladder afferent neurons in the present study. It has been reported that, in cultured DRG neurons, NGF can acutely (in minutes) enhance TTX-resistant $\mathrm{Na}^{+}$current activity along with increased cell firing by activation of the sphingomyelin signaling pathway (Zhang et al., 2002). Increased amplitude of TTX-resistant $\mathrm{Na}^{+}$currents was also reported in sensory neurons from nodose ganglia cultured with NGF for $1 \mathrm{~d}$ (Bielefeldt et al., 2003). However, increased mRNA levels of $\mathrm{Na}_{\mathrm{v}} 1.8$, the predominant TTX-resistant $\mathrm{Na}^{+}$channel $\alpha$ subunit in bladder af- ferent neurons (Black et al., 2003), were not observed in DRG neurons $1 \mathrm{~d}$ after systemic application of NGF, but were detected in DRG neurons when cultured with NGF for $7 \mathrm{~d}$ (Okuse et al., 1997). Thus, it seems likely that acute effects of NGF on TTXresistant $\mathrm{Na}^{+}$currents are mediated by modulation mechanisms that involve activation of second messenger signaling pathways and/or direct interactions with the channels, whereas prolonged exposure to NGF can increase TTX-resistant $\mathrm{Na}^{+}$channel expression by transcriptional modification mechanisms in sensory neurons (McCleskey and Gold, 1999; Woolf and Salter, 2000). Because in a rat model of inflammatory hindpaw pain the expression of $\mathrm{Na}_{\mathrm{v}} 1.8$ in DRG neurons was increased along with an increase in TTX-resistant $\mathrm{Na}^{+}$current density (Tanaka et al., 1998), the increased amplitude of TTX-resistant $\mathrm{Na}^{+}$currents after 2 week NGF treatment may contribute to increased excitability of C-fiber bladder afferent neurons in this study. However, despite the increased amplitude of TTX-resistant $\mathrm{Na}^{+}$currents, the current density (i.e., normalized conductance) of TTXresistant $\mathrm{Na}^{+}$channels was not significantly altered because 2 week NGF application also induced cell hypertrophy of bladder afferent neurons (Table 3). Regarding the interpretation of increased $\mathrm{Na}^{+}$current amplitude and cell size in NGF-treated bladder neurons, one might argue that NGF did not change the absolute size of the neurons, but rather shifted the distribution of TTX-resistant $\mathrm{Na}^{+}$channels toward the neurons with larger size. However, this is not likely to be the case because the proportion of capsaicin-sensitive cells with TTX-resistant spikes among bladder afferent neurons was not different $(\sim 70 \%)$ in control and NGF-treated animals in this study. In addition, somal hypertrophy in bladder afferent neurons was observed in rats with spinal cord injury or bladder outlet obstruction, which exhibited bladder overactivity and increased NGF levels in the bladder and bladder afferent pathways (Steers et al., 1991, 1996; Kruse et al., 1995; Yoshimura and de Groat, 1997; Seki et al., 2002), and autoimmunization against NGF suppresses bladder afferent neuron hypertrophy in animals with bladder outlet obstruction (Steers et al., 1991, 1996). Somal hypertrophy and hyperexcitability of nociceptive afferent neurons have also been demonstrated in rats with chemically induced ileitis (Moore et al., 2002). Moreover, in previous studies using NGF overexpression transgenic mice, mRNA levels of $\mathrm{Na}_{\mathrm{v}} 1.8$ as well as $\mathrm{Na}_{\mathrm{v}} 1.9$ were significantly increased, although the TTX-resistant $\mathrm{Na}^{+}$current density was not changed in DRG neurons, which had larger somata, compared with wild-type mice (Goodness et al., 1997; Fjell et al., 1999). Thus, it could be speculated that long-term exposure of NGF has a role in the maintenance of cell excitability by distributing TTXresistant $\mathrm{Na}^{+}$channels over a larger surface area of hypertrophied sensory neurons.

In conclusion, the present study provided direct evidence indicating that in vivo long-term exposure of NGF to bladder afferent pathways can induce a reduction in A-type $\mathrm{K}^{+}$current density and hyperexcitability of $\mathrm{C}$-fiber bladder afferent neurons, resulting in bladder overactivity. Thus, targeting NGF expression in afferent pathways could be an effective modality for the treatment of bladder overactivity and nociceptive conditions.

\section{References}

Akins PT, McCleskey EW (1993) Characterization of potassium currents in adult rat sensory neurons and modulation by opioids and cyclic AMP. Neuroscience 56:759-769.

Bielefeldt K, Ozaki N, Gebhart GF (2003) Role of nerve growth factor in modulation of gastric afferent neurons in the rat. Am J Physiol 284:G499-G507.

Black JA, Cummins TR, Yoshimura N, de Groat WC, Waxman SG (2003) 
Tetrodotoxin-resistant sodium channels $\mathrm{Na}_{\mathrm{v}} 1.8 / \mathrm{SNS}$ and $\mathrm{Na}_{\mathrm{v}} 1.9 / \mathrm{NaN}$ in afferent neurons innervating urinary bladder in control and spinal cord injured rats. Brain Res 963:132-138.

Chancellor MB, Yoshimura N (2002) Physiology and pharmacology of the bladder and urethra. In: Campbell's urology, Ed 8 (Walsh PC, Retik AB, Vaughan C, Wein A, eds), pp 831-886. Philadelphia: Saunders.

Dang K, Bielefeldt K, Gebhart GF (2004) Gastric ulcers reduce A-type potassium currents in rat gastric sensory ganglion neurons. Am J Physiol 286:G573-G579.

Dupont MC, Spitsbergen JM, Kim KB, Tuttle JB, Steers WD (2001) Histological and neurotrophic changes triggered by varying models of bladder inflammation. J Urol 166:1111-1118.

Elliott AA, Elliott JR (1993) Characterization of TTX-sensitive and TTXresistant sodium currents in small cells from adult rat dorsal root ganglia. J Physiol (Lond) 463:39-56.

Everill B, Kocsis JD (1999) Reduction in potassium currents in identified cutaneous afferent dorsal root ganglion neurons after axotomy. J Neurophysiol 82:700-708.

Everill B, Rizzo MA, Kocsis JD (1998) Morphologically identified cutaneous afferent DRG neurons express three different potassium currents in varying proportions. J Neurophysiol 79:1814-1824.

Fjell J, Cummins TR, Davis BM, Albers KM, Fried K, Waxman SG, Black JA (1999) Sodium channel expression in NGF-overexpressing transgenic mice. J Neurosci Res 57:39-47.

Gold MS, Shuster MJ, Levine JD (1996) Characterization of six voltage gated $\mathrm{K}^{+}$currents in adult rat sensory neurons. J Neurophysiol 75:2629-2646.

Goodness TP, Albers KM, Davis FE, Davis BM (1997) Overexpression of nerve growth factor in skin increases sensory neuron size and modulates Trk receptor expression. Eur J Neurosci 9:1574-1585.

Hall A, Stow J, Sorensen R, Dolly JO, Owen D (1994) Blockade by dendrotoxin homologues of voltage-dependent $\mathrm{K}^{+}$currents in cultured sensory neurones from neonatal rats. Br J Pharmacol 113:959-967.

Hu VY, Zvara P, Dattilio A, Redman TL, Allen SJ, Dawbarn D, Stroemer RP, Vizzard MA (2005) Decrease in bladder overactivity with REN1820 in rats with cyclophosphamide induced cystitis. J Urol 173:1016-1021.

Kruse MN, Bray LA, de Groat WC (1995) Influence of spinal cord injury on the morphology of bladder afferent and efferent neurons. J Auton Nerv Syst 54:215-224.

Lamb K, Gebhart GF, Bielefeldt K (2004) Increased nerve growth factor expression triggers bladder overactivity. J Pain 5:150-156.

McCleskey EW, Gold MS (1999) Ion channels of nociception. Annu Rev Physiol 61:835-856.

McFarlane S, Cooper E (1991) Kinetics and voltage dependence of A-type currents on neonatal rat sensory neurons. J Neurophysiol 66:1380-1391.

Moore BA, Stewart TM, Hill C, Vanner SJ (2002) TNBS ileitis evokes hyperexcitability and changes in ionic membrane properties of nociceptive DRG neurons. Am J Physiol 282:G1045-G1051.

Okragly AJ, Haak-Frendscho M (1997) An acid-treatment method for the enhanced detection of GDNF in biological samples. Exp Neurol 145:592-596.

Okuse K, Chaplan SR, McMahon SB, Luo ZD, Calcutt NA, Scott BP, Akopian AN, Wood JN (1997) Regulation of expression of the sensory neuronspecific sodium channel SNS in inflammatory and neuropathic pain. Mol Cell Neurosci 10:196-207.

Seki S, Sasaki K, Fraser MO, Igawa Y, Nishizawa O, Chancellor MB, de Groat WC, Yoshimura N (2002) Immunoneutralization of nerve growth factor in lumbosacral spinal cord reduces bladder hyperreflexia in spinal cord injured rats. J Urol 168:2269-2274.

Seki S, Sasaki K, Igawa Y, Nishizawa O, Chancellor MB, De Groat WC, Yoshimura N (2004) Suppression of detrusor-sphincter dyssynergia by immunoneutralization of nerve growth factor in lumbosacral spinal cord in spinal cord injured rats. J Urol 171:478-482.

Steers WD, Kolbeck S, Creedon D, Tuttle JB (1991) Nerve growth factor in the urinary bladder of the adult regulates neuronal form and function. J Clin Invest 88:1709-1715.

Steers WD, Creedon DJ, Tuttle JB (1996) Immunity to nerve growth factor prevents afferent plasticity following urinary bladder hypertrophy. J Urol 155:379-385.

Stewart T, Beyak MJ, Vanner S (2003) Ileitis modulates potassium and sodium currents in guinea pig dorsal root ganglia sensory neurons. J Physiol (Lond) 552:797-807.

Tanaka M, Cummins TR, Ishikawa K, Dib-Hajj SD, Black JA, Waxman SG (1998) $\mathrm{SNS} \mathrm{Na}^{+}$channel expression increases in dorsal root ganglion neurons in the carrageenan inflammatory pain model. NeuroReport 9:967-972.

Vizzard MA (2000) Changes in urinary bladder neurotrophic factor mRNA and NGF protein following urinary bladder dysfunction. Exp Neurol 161:273-284.

Woolf CJ, Salter MW (2000) Neuronal plasticity: increasing the gain in pain. Science 288:1765-1769.

Yaksh TL, Durant PA, Brent CR (1986) Micturition in rats: a chronic model for study of bladder function and effect of anesthetics. Am J Physiol 251:R1177-R1185.

Yang EK, Takimoto T, Hayashi Y, de Groat WC, Yoshimura N (2004) Altered expression of potassium channel subunit mRNAs and $\alpha$-dendrotoxin sensitivity of potassium currents in rat dorsal root ganglion neurons after axotomy. Neuroscience 123:867-874.

Yoshimura N (1999) Bladder afferent pathway and spinal cord injury: possible mechanisms inducing hyperreflexia of the urinary bladder. Prog Neurobiol 57:583-606.

Yoshimura N, de Groat WC (1997) Plasticity of $\mathrm{Na}^{+}$channels in afferent neurones innervating rat urinary bladder following spinal cord injury. J Physiol (Lond) 503:269-276.

Yoshimura N, de Groat WC (1999) Increased excitability of afferent neurons innervating rat urinary bladder following chronic bladder inflammation. J Neurosci 19:4644-4653.

Yoshimura N, White G, Weight FF, de Groat WC (1994) Patch clamp recordings from subpopulations of autonomic and afferent neurons identified by axonal tracing techniques. J Auton Nerv Syst 49:85-92.

Yoshimura N, White G, Weight FF, de Groat WC (1996) Different types of $\mathrm{Na}^{+}$and $\mathrm{K}^{+}$currents in rat dorsal root ganglion neurons innervating the urinary bladder. J Physiol (Lond) 494:1-16.

Yoshimura N, Erdman SL, Snider MW, de Groat WC (1998) Effects of spinal cord injury on neurofilament immunoreactivity and capsaicin sensitivity in rat dorsal root ganglion neurons innervating the urinary bladder. Neuroscience 83:633-643.

Yoshimura N, Bennet NE, Phelan MW, de Groat WC (1999) Effects of chronic nerve growth factor treatment on rat urinary bladder and bladder afferent neurons. Soc Neurosci Abstr 25:772.12.

Yoshimura N, Seki S, Chancellor MB, de Groat WC, Ueda T (2002) Targeting afferent hyperexcitability for therapy of the painful bladder syndrome. Urology 59 [5 Suppl 1]:61-67.

Yoshimura N, Seki S, Erickson KA, Erickson VL, Chancellor MB, de Groat WC (2003) Histological and electrical properties of rat dorsal root ganglion neurons innervating the lower urinary tract. J Neurosci 23:4355-4361.

Zhang YH, Vasko MR, Nicol GD (2002) Ceramide, a putative second messenger for nerve growth factor, modulates the TTX-resistant $\mathrm{Na}^{+}$current and delayed rectifier $\mathrm{K}^{+}$current in rat sensory neurons. J Physiol (Lond) 544:385-402. 